\title{
BIM Technology of Refined Construction Research on the Construction Application
}

\author{
Jifu Lu ${ }^{\mathrm{a}}$ \\ Huali College Guangdong University of Technology,Guangzhou 511325, China. \\ a359205454@qq.com.
}

Keywords:BIM technology, construction engineering, refinement, construction

\begin{abstract}
BIM technology is a kind of simulation imaging technology, which has the characteristics of strong visibility, good coordination, and powerful graphics. Especially in the construction industry, this technology can make the construction of the project more efficient and has rapid results. When BIM technology is used, project information can be projected onto a three-dimensional model, which makes it convenient and reliable for each work to be carried out, which is of great significance to the development of the construction industry.
\end{abstract}

\section{Introduction}

This paper first analyzes the BIM technology, and then elaborates the construction and installation based on refinement. The BIM technology demonstrates the technical strength of the enterprise and improves the project winning bid rate. The BIM technology is used to enhance the fine management of the enterprise and enhance the project profit. The BIM technology is easy to solve complexities. Project technical problems, speed up the progress of the project, improve the quality of the project, so that enterprises occupy a technological superiority in the competition. The application scope of BIM technology in the current stage of China's construction industry is mainly in the design and construction phase. Research on BIM technology during the construction phase can promote the extension of $\mathrm{BIM}^{[1]}$ technology from the design phase to the construction phase and reduce the attenuation in the information transmission process. Can improve the project management level, to achieve refined construction management requirements. Therefore, it is very necessary to study the BIM technology in the fine construction management.

\section{The significance of BIM technology in the field of construction}

BIM can provide reliable knowledge resources and integrated information sharing for the entire life cycle of a building. Its core concept is to create almost all data building information models that can be recorded during project implementation. The establishment of the entire life cycle of construction projects and the data integration of building information are the foundation for the implementation of BIM technology ${ }^{[2]}$. Through the effective integration of building information and the establishment of three-dimensional models, the construction of various projects and constructions within a construction project is completed. Information sharing at all stages, thereby increasing production efficiency and resource utilization ${ }^{[3]}$.

The information technology capabilities of BIM technology can improve the accuracy of early forecasting, speed up information processing, facilitate the sharing of data by participants, and facilitate information transfer at all stages. BIM has features such as visualization, coordination, simulation, optimization, and graphing. Compared with traditional 2D drawings, the BIM model can display building information more intuitively and in detail, so that multiple participants can easily discuss a professional design result. 


\section{The promotion and application of BIM technology in China}

The promotion and application of BIM technology in China is still in its infancy. However, with reference to the development of the construction industry in developed countries in Europe and America, with the successive introduction of relevant national policies and the guidance and support of the construction authorities, there is bound to be a broader development in the future. Space will inevitably become the goal and direction of the development of the construction industry. The construction phase of the construction project involves a large number of participants. The time span is long, there are many influencing factors ${ }^{[4]}$, there are many uncertain factors, and the amount of information is also very large. There are many types of information, and how to effectively use this information is a serious problem for project managers. In the construction phase, the traditional construction drawings have a low degree of visualization, and they cannot express construction products directly, which also causes some problems for the management of the project construction phase. BIM technology can play the biggest value in the construction phase of a construction project and provide a collaborative sharing and exchange platform for engineering data. The combination of BIM technology and construction project management is a policy orientation and an inevitable trend of development. How to use BIM technology in construction management is closely linked with the future development direction ${ }^{[5]}$.

\section{BIM project model technology overview building information model}

BIM is a product of the construction industry that accompanies the booming development of computer technology. BIM technology can be understood in three ways:

(1) The computer three-dimensional building information model means that the two-dimensional CAD drawings are converted into a three-dimensional building information model, so that the drawing information of different professions such as architecture, structure, and hydro power is integrated into a three-dimensional building information model, which facilitates the overall construction information. View

(2) The application of building information model is to realize parametric model application, use 3D building information model to realize design optimization, pipeline integration, virtual construction, project volume calculation, etc., to continuously mine the value of the model and solve the new technical challenge;

(3) The management of the building information model platform means building a digital project management platform based on the three-dimensional information model, synergistic the design management, cost management, quality and safety management with the project management platform, and implementing the model-based Platform, paperless office, fine management, so as to improve project management efficiency.

\section{Application of BIM Technology in Refined Construction}

\section{(1) Application of BIM Technology in Cost Control}

The construction unit uses the 3D relational database established by BIM to establish relationships with time, space, and process dimensions of cost-related data. It can quickly, accurately, and efficiently complete the calculation of all components in the model and automatically generate project calculations, combined with the BIM database ${ }^{[6]}$. The price information of labor, materials, machinery, etc. in the analysis of construction costs at any location and at any period of time, thereby rapidly formulating project schedules, capital plans, etc., rationally deploying resources, effectively guiding construction costs in actual production, and Fine management of construction costs.

\section{(2) Application of BIM Technology in Progress Control}

The 4D technology that imports the construction schedule in the BIM model can check whether the schedule is reasonably arranged to adjust the schedule of the project to meet the overall time-node requirements. The adjusted three-dimensional model and the optimized four-dimensional virtual 
building animation are displayed to the project managers and construction personnel, so that they can more intuitively understand the specific conditions of the project and the entire construction management process, enabling them to understand the design intent and construction plan in a deeper understanding. Requirement to reduce unnecessary errors in the construction process due to information transmission. This not only improves the quality of project construction, but also speeds up construction progress.

Work Matters

Work based on BIM technology

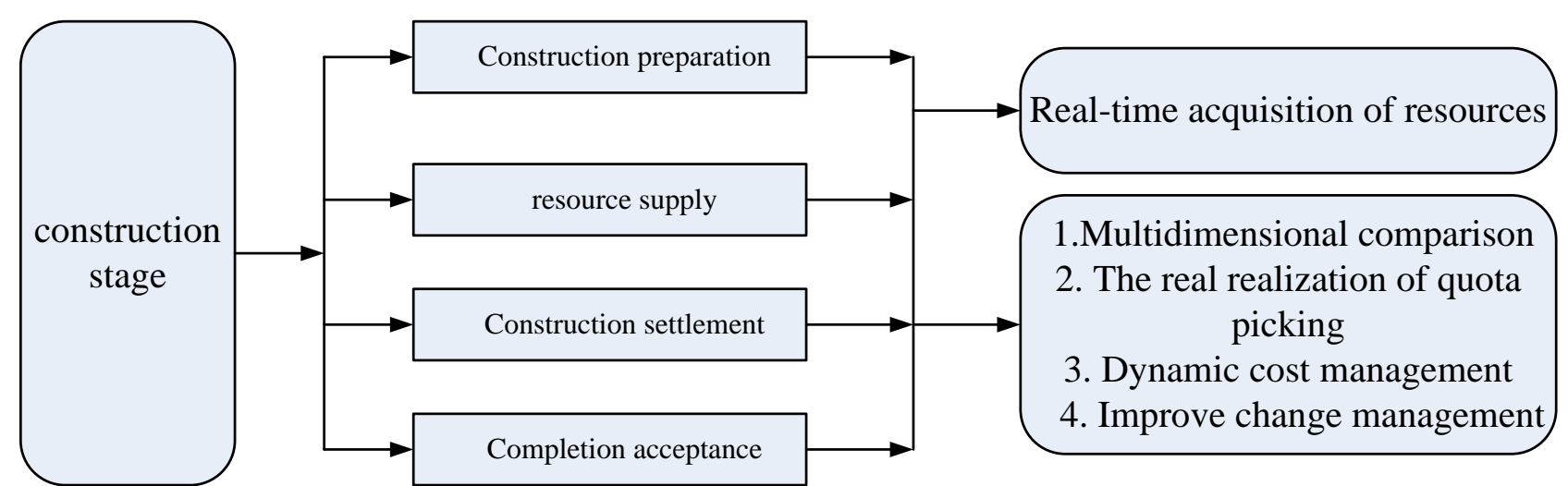

Fig. 1 Construction system based on BIM

\section{(3) Application of BIM Technology in Quality Control}

The construction unit uses the established 4D information model virtual construction technology to simulate and display the construction sequence and construction organization of the project. At the same time, it can identify possible interference and collisions in its construction plan, intuitively understand the key points of construction quality control, and reduce the number of projects. Rework in construction. During the construction process, the staff timely entered the project quality problems (the location, time, and processing of the quality) into the BIM model. The relevant staff can track in real time to achieve dynamic process control of quality and improve construction quality. In terms of safety control, we can clearly see the borders and muti-operating cross-hazards areas in the model, and we can make safety protection for the edge openings in advance, and isolate the multiple-risk areas at the same time; when the safety is at the bottom, make each project manager and The construction personnel had a good idea of the danger zone and had to take precautions beforehand. At the same time, the dangerous area of the entire construction site can be dynamically updated to achieve dynamic safety control.

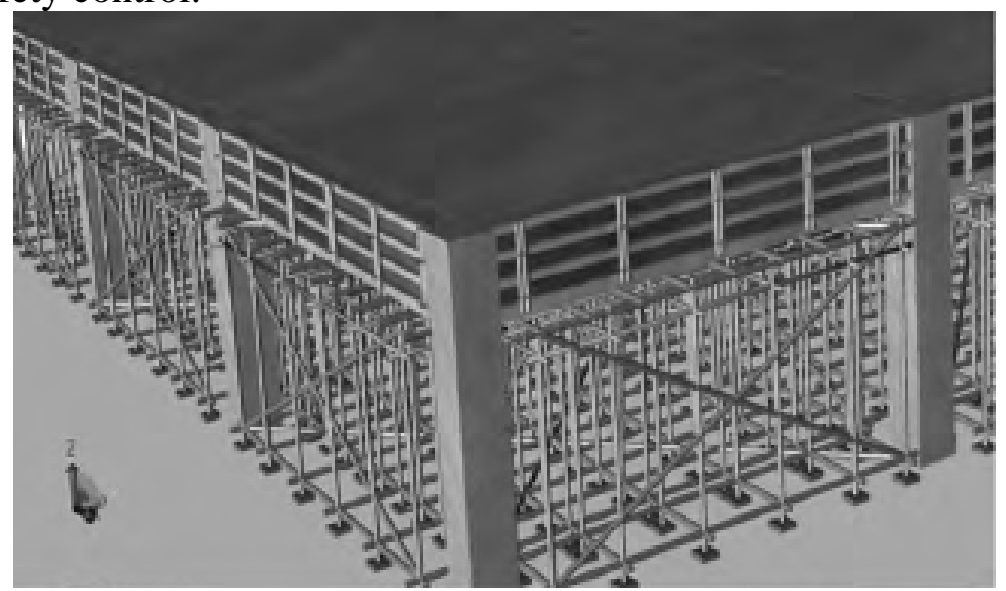

Fig. 2 Specify the amount of material used in the construction area 


\subsection{Construction progress management based on BIM}

The construction schedule planning based on BIM adds time dimension information on the basis of the established three-dimensional model, makes a construction four-dimensional progress model, uses the four-dimensional construction progress model to simulate the construction process, and forms an animation form. The construction manager can optimize the construction plan directly by watching the construction animation.

When using the 4D construction schedule simulation, the 3D model is associated with the time progress, the 4D model is established, the construction crossbar diagram is built in the project, and then the projected crossbar diagram is imported into Navisworks.

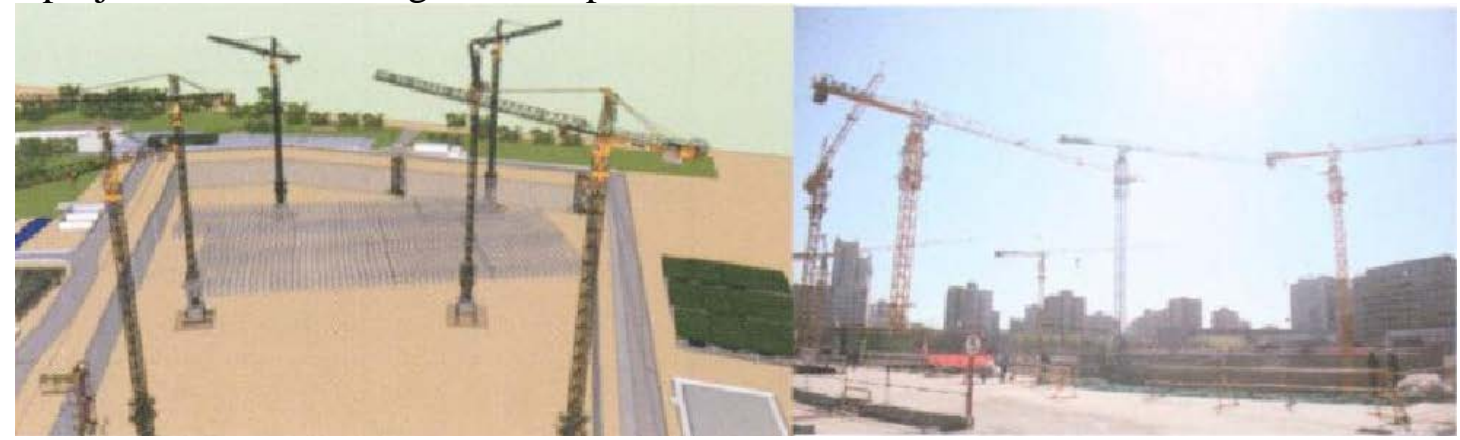

Fig. 3 Comparison of BIM Construction Site Arrangement Model and Actual Construction Site Photographs

Through the 4D progress model established by project and Navisworks, the construction progress of the medical ward building from the basement to the standard floor was simulated, and the construction process of the building was intuitively seen. The construction simulation process is presented in the form of an animation. Through simulation, the construction manager can intuitively grasp the construction process and can formulate a reasonable construction schedule accordingly, and can better control the key construction processes. Through the advance preview of the construction process, we can effectively grasp the nodes of the key processes in the construction and reduce the occurrence of risks.

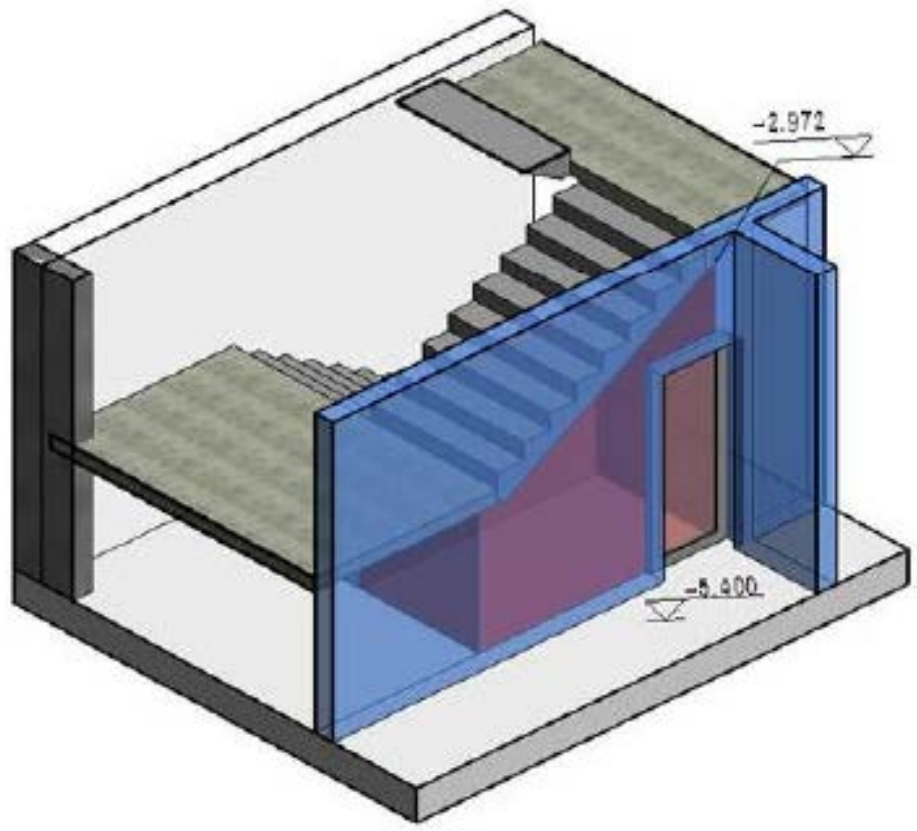

Fig. 4 Using Naviswork for Construction Schedule Simulation 


\subsection{Influence of BIM Technology on the Quality of Construction Projects}

BIM technology is of great significance for realizing the fine construction of engineering buildings. It can comprehensively grasp the basic information for engineering projects, and relates to the quality and safety of engineering buildings and modern construction technologies. A large amount of work is done at the construction site, after the application of BIM technology, Will be able to achieve part of the construction work factory. In other words, using BIM technology to build models, the construction of components, such as various types of components or pipelines, etc., are per-manufactured into semi-finished products at the factory. Through reasonable optimization of the construction process, the assembly and installation are performed on site, thereby reducing on-site construction time. Improve work efficiency at the site.

The construction process of the engineering entity needs to complete the construction phase. The quality of the completion of the construction phase is to guarantee the core quality assurance of the final project construction. Therefore, the normal operation of the construction process is ensured, and the construction quality is the main work of the project quality.

\section{(1) The construction quality is guaranteed through 4D simulation.}

BIM 3D model building All the information of the building can generate the flat, cutaway and elevation drawings of the building directly through the software platform. The 3D model of BIM has the characteristics of visualization and intuition. In the traditional construction organization process, it is Using Gantlet Chart, the method has a low degree of visualization. When large and complex projects are encountered, it is difficult to achieve a complete grasp of the construction process, and it is difficult to deal with complicated construction relationships. It is not very good for the project. The dynamic effect of the construction is handled ${ }^{[8]}$. The use of BIM four-dimensional construction simulation can be more clear, intuitive and accurate analysis of the construction process, while the dynamic conditions of control can also meet the requirements. Its main features include: First, it can analyze the preparatory work before construction. In the construction preparation stage, the four-dimensional simulation technology can be used to simulate the real construction scenario. It is useful for the contradiction and conflict between various construction procedures. The appropriate adjustment work can be carried out, and the software can also compare different construction processes and select the optimal construction plan for implementation. Secondly, the control during the construction process can use the corresponding functions of the software to simulate the time axis, compare the construction plan with the actual project implementation, and make timely changes when there is a deviation. The prevention and control affect the normal construction and engineering of the construction. Quality issues.

\section{(2) Construction safety protection}

3D visualization security protection. Using the three-dimensional model that has been built, it can be clearly seen which of the prong openings need to be protected, and the protection is added to the three-dimensional model to guide the safety of the construction site. At the same time, it can also provide visual operations for safe delivery.

\subsection{Guarantee the quality of the completion.}

For the construction model delivered by the designer, the construction unit can perform real-time maintenance on the design model according to the corresponding design change requirements and technical review conditions, so that when the project is completed, the BIM completion model can also be completed. The BIM completion model enables the sudden inspection of the use of the subsequent project. When using BIM to perform collision inspections on the construction, two types of inspections are mainly performed, namely soft collision and hard collision. Most of the hard hitting is used to check the collision problem in the pipeline. The soft collision is a gap collision. The user can set the collision distance by himself. It is commonly used to perform clearance inspection. By superimposing the electromagnet model and the civil model, collision detection is performed in the software, and the pipeline is adjusted according to the principle of comprehensive piping to avoid different system pipelines. Collisions between pipelines and structures, coordination of the requirements of the direct pipeline layout of various specialties, and the coordination of various professional pipeline construction operations, BIM application engineers automatically detect the 
location of the structure reserved holes after the model is superimposed and automatically Generate statistics tables.

After checking, the engineers will release all reserved hole locations and quantities to the relevant labor service teams and project management personnel through technical disclosure. Therefore, the use of BIM technology will reduce the construction costs, speed up the progress of the construction period, improve the construction accuracy, and bring fine management to the construction.

With the continuous development and progress of society, people' s unique requirements for architecture have become higher and higher. As a result, more and more complex projects are beginning to emerge. It is difficult for such projects to use traditional 2D drawings to fully recognize the completeness. . In the installation process, a certain part of the components often cannot be used due to design problems or processing problems that cannot be used, and must be returned to the factory for modification. This will seriously affect the normal schedule and increase the cost of the project. Using BIM 3D solid model can use the computer to pr-assemble the process of designing, processing, and installation. After the normal installation is completed, operations such as machining are performed, which largely avoids the occurrence of design problems of the components.

\section{Conclusion}

To sum up, the refined construction management based on BIM technology is based on visualization technology and computerization, and all information possessed by the project can be integrated by computer, and any information on the project can be inquired in real time. The ultimate value of BIM is to provide an integrated interactive project information environment, improve the efficiency of collaborative work, simulate the situation of the construction site in the computer, bring visual management for project management, use BIM technology to improve the construction quality, strictly control the construction progress, and conserve resources. , shorten the construction period and reduce costs and increase efficiency.

\section{Acknowledgments}

This work was financially supported by In 2014, the teaching quality and teaching reform project of Guangdong provincial undergraduate university and the construction of experimental teaching center for civil engineering(Cantonese high school letter [2014]97). The first batch of production and study cooperation and collaborative education project in 2017, the Ministry of education and higher education, the construction of Virtual Simulation Training Center for building engineering(letter of high school [2017] No. 37 201701061027) fund.

\section{References}

[1]. Sun Yue, et al.Research on Lifecycle Information Management of Construction Project Based on BIM. Harbin: Harbin Institute of Technology Vol. 3 (2011) No. 7, p.13-18.

[2]. Li Yujuan, et al.Application of BIM Technology in Residential Building Design . Chongqing: Chongqing University, Vol. 12 (2008) No. 5, p.39-53.

[3]. Zhang Chunxia, et al. BIM technology application status and development obstacles in China's construction industry . Construction Economics, Vol. 5 (2011) No. 9.96-98.

[4]. Wang Guangbin, Zhang Yang, Tan Dan, et al.BIM-based engineering project cost accounting theory and implementation methods. Science and Technology Progress and Countermeasures,Vol. 3 (2009) No. 4, p.47-49.

[5]. Niu Bosheng, et al.Application of BIM technology in project project schedule management . Chongqing: Chongqing University,Vol.2 (2012) No.6, p.40-63. 
[6]. Li Yadong, Lang Yichuan, Wu Tianhua, et al.Engineering quality management based on BIM implementation . Construction Technology, Vol. 9 (2013) No.13, p.20-22+112.

[7]. Zhu Yana, Wang Yiwe, et al. Engineering project safety management development status and trend analysis . Times Finance, Vol. 8 (2013) No.1, p.64-65.

[8]. Yellow manganese steel, Peng Wang, et al.The application value of BIM in the management of general contracting project construction. Civil Engineering Information Technology, Vol.8(2013) No. 10, p.87-91. 